\title{
Analysis of U2's Concert Performance Location Choice: Application of an Adapted Gravity Model
}

\author{
Joel I. Deichmann ${ }^{1}$ \\ ${ }^{1}$ Global Studies Department, Bentley University, Waltham, Massachusetts, USA \\ Correspondence: Joel I. Deichmann, Global Studies Department, Bentley University, Waltham, Massachusetts, \\ USA. E-mail: jdeichmann@bentley.edu
}

Received: September 9, 2014

Accepted: October 10, 2014

Online Published: October 25, 2014

doi:10.5539/ibr.v7n11p190

URL: http://dx.doi.org/10.5539/ibr.v7n11p190

\begin{abstract}
The rock band U2, based in Dublin, Ireland, has become one of the most successful touring acts in the history of live music. Treating U2 as a global business enterprise, this paper introduces a gravity approach to understanding performance location selection. A brief descriptive analysis of the band's tour geography is followed by the presentation of results from linear regression models that evaluate the choice of countries for live performances. Over 33 years, U2 played more than one thousand six hundred concerts at locations in 40 countries. Having completed several world tours with multiple legs, U2 has developed a clear geographical circuit, performing mainly in Europe, North America, and Oceania. Findings from the models indicate that the band is attracted primarily by market size (presence of large urban areas) and market strength (income). In addition, the band's location choices appear to be governed by cultural proximity. Counter to expectations, neither geographical distance nor country risk appear to play a significant role in the selection of tour destinations, especially in the most recent $U 2360$ tour of 2009-2011. This interdisciplinary paper demonstrates the application of an adapted gravity approach--often employed in economics--to better understand music geography, an area traditionally dominated by cultural geographers.
\end{abstract}

Keywords: gravity model, location analysis, music geography, U2

\section{Introduction}

The musical career of U2 spans four decades, and based upon ticket sales for their U2360 ${ }^{\circ}$ tour of 2009-2011, the band is among the most successful performing acts in history. As such, U2 can be considered as a business enterprise that is subject to the same considerations as other transnational corporations. In particular, U2's strategic decision-making includes site selection for concert tours (Waddell, Barnet \& Berry, 2007). Digital and streaming music formats have transformed the music industry, reorienting major acts away from the sale of recordings and toward the sale of concert tickets. In the case of U2, according to Boyd (2013) "album sales no longer really matter much. Sales of tickets for (U2's) world tour, which is due to begin (soon), really do." This development seems to be verified by U2's September 2014 surprise giveaway of its new album Songs of Innocence to hundreds of millions of Apple product owners (O'Shea, 2014). Moreover, Earl (2001) argues that live performances will remain relevant because they offer a level of experience that supports an enduring demand for live music, although major costs can be avoided by limiting one's listening habits to recordings.

Concert tours represent a form of spatial interaction between performers and audiences. Each performing act has an absolute spatial origin (Dublin, Ireland in U2's case) and its management decides upon other locations for concerts, subject to the parameters of the music industry. Markets and logistics are considered carefully before band management finalizes location decisions. Ostensibly, the goal of the concert tour is to earn revenue (Waddell et al., 2007; Boyd, 2013), although this may vary over time and depend upon other circumstances. For example, while increasing exposure for itself as a relatively unknown band, U2's objective in appearing at Live Aid in 1984 was one of social conscience: to join other performers in drawing attention to Africa's famine. Similarly, U2's 1997 concert in Sarajevo was intended to bring media attention to a city under siege for more than three years during Yugoslavia's war of dissolution (Carter, 2005). Years later in 2004, U2 participated in the Live 8 mega-concert to help lobby world leaders to attend to Africa's AIDS epidemic. Nevertheless, under normal circumstances any band's primary purpose for touring is to earn money. This can be achieved either directly through selling tickets to performances, or indirectly by promoting recorded material to live audiences. 


\section{Literature}

Music geography is a subfield of cultural geography, to which numerous researchers have made commendable contributions. Nash and Carney (1996) identify seven themes of music geography, including origins of music, world distribution, location analysis, source areas, trends based upon electricity, impact of music on landscapes, and global music. After reviewing studies in these seven areas, the authors suggest an emerging theme of "technological innovations", an area that has even advanced dramatically due to digital format and streaming audio since the paper was written. Of greatest relevance to the present research is a short discussion on location analysis, or the examination of spatial aspects of musical activities such as musicians' compositions and travel behavior. Nash and Carney's work therefore helps position the present paper within the literature of music geography.

Johansson and Bell (2009) offer a collection of essays in a book they describe as being at the intersection of music and geography. Written mainly by geographers and focusing on popular music, the volume contains case studies from locations around the world. While most of the essays assess the ways in which musical styles and lyrics reflect location, Johansson and Bell provide an analysis of the geography of new U.S. music scenes that highlights localized factors that are conducive to success for new bands. Relevant to the present research is the authors' observation that certain large cities tend to have "better" music scenes than others, and this has implications upon a city's ability to attract touring bands.

Echoing the call for scholars to pay closer attention to the physical spaces of performance and how they reflect the power relations of organizers, Wood, Duffy, and Smith (2007) critically examine the problematic nature of concerts-for-profit. Presenting qualitative data collected from concertgoers, they argue that "it is the money that drives the materials and meaning of performance" (871).

Florida and Jackson (2010) assess the location of musicians and establishments in American cities. Using location quotients, they examine the distribution of music employment and establishments in 1970 and 2004 relative to city size. The authors find evidence that large markets offer economic and artistic advantages that cause artists to agglomerate in industry-leading cities including New York, Los Angeles, and Nashville.

Similarly, but on a global scale, Brandellero and Pfeffer (2011) consider European world music charts and award nominations as measures for examining economic and geographical linkages in world music production. The authors identify increasing diversification in the geography of music production toward places including Brazil, South Africa, and India. Concurrently, they discover that musical content has shifted from its origins toward large urban areas in Europe and the United States, including New York, London, Paris, Berlin, and Munich, where heavy concentrations of cultural industries can be found.

Florida, Mellander, and Stolarick (2012) study the geography of the U.S. entertainment industry from 1970-2000, and argue that it can be explained not only by geographies of scale, but also those of scope. In other words, cities like New York and Los Angeles dominate the entertainment industry thanks to their local abundance of skills, inputs, and capabilities that support the entertainment industry. Because of these localized factors, the clustering of entertainment in these two cities is far greater than would be expected by their population size alone. The authors argue that because of technological change and globalization, however, some disbursement of activities is increasingly taken place, especially as individual genres become associated with niche markets.

More recently, Johansson and Bell (2014) use data from concert performances between 2006 and 2008 to identify touring hierarchies among popular music acts. The authors highlight the importance of metropolitan size, relative location, and demographic and cultural features. Using cluster analysis, they conclude that the "best places" for rock bands to perform include San Francisco, Austin, and Portland, echoing earlier work by Florida et al. (2012). Among the strengths of their findings is the study's representativeness; it includes 12,000 performances. Unfortunately, Johansson and Bell examine only North American cities, and the performances they consider are limited to a three year time period. While Johansson and Bell's (2014) findings undeniably contribute to a broad understanding of tours over a short period of time, the present study favors a detailed look at a single rock band in forty countries over a period of 33 years.

\subsection{U2 as a Dublin-Based Business Enterprise}

Similar to corporate executives who invest directly overseas, U2 faces the challenge of managing a global business. Waddell et al. (2007) provide an overview of the considerations band management faces in concert promotion and touring. Their book makes numerous references to $\mathrm{U} 2$, and pays particular attention to the Vertigo tour of 2005-2006. Unfortunately, Waddell et al. (2007) do not delve into concert site selection by U2 specifically. Nevertheless, among their guide's greatest relevance to the present research is a chapter on why, 
when, and where bands should tour (pp. 41-54). In general terms, this chapter raises considerations on which markets to play, the parameters of pre-existing popularity, international or domestic scope, types of venues, and tour routing. Because of U2's popularity, over recent years the band has been inclined to play only major markets that offer workable availabilities at large arenas $(15,000-20,000)$ and stadiums $(15,000-100,000)$. In addition, the authors go into considerable detail in examining issues such as transporting, housing, protecting, and feeding large crews on major tours.

As a global business, U2's management faces other location decisions as well. In 2006, U2 moved its main operations off-shore to the Netherlands for tax purposes (Boyle, 2011). This sort of spatial strategy is often practiced among multinational corporations. Amid widespread accusations of avoiding Irish taxes and being disloyal to its home country, Manager Paul McGuinness defends U2's actions by pointing out that "at least 95 percent of U2's business - including record and ticket sales - takes place outside of Ireland, and as a result the band pays many different kinds of taxes all over the world," adding that the band remains "Ireland-based" (Boyle, 2011).

Similarly, U2 itself routinely reiterates its connection to Ireland as "home." For example, on July 4, 1987, Bono ad libs during the song "40," to clarify to the audience that U2 is indeed Irish, perhaps to avert any language-related assumptions that the band is English.

I hope that in the future I have the good manners to speak your language as good [sic] as you speak my language. But don't forget, we're an Irish band, alright? (Transcription obtained from www.u2wanderer.org)

Similarly, recorded on their U2 Go Home (Live from Slane Castle, 2003) DVD, Bono reaffirms loyalty to Dublin during "Out of Control:"

There's some big ideas. Father, I need a lend of 500 pounds 'cause we're gonna go over to London. We're gonna score ourselves a record deal. And when we get our record deal, we're not gonna [sic] stay in London. We're not gonna go to New York City. We're gonna stay and base our crew in Dublin 'cause these people...this is our tribe! (Transcription obtained from www.atu2.com)

Having established U2 as a Dublin-based enterprise, we can now ask questions about where they choose to perform and why. In doing so, we are assuming that U2's decisions are motivated in large part by profits. We can infer from Waddell et al. (2007), and Boyd (2013), that given U2's present stature and the nature of popular music, profits are primarily achieved through touring the world from the band's base in Dublin, Ireland.

\subsection{Patterns and Explanations of U2's Geography of Performance}

This paper's two goals are to describe U2's touring patterns and analyze factors that explain them, drawing upon the gravity models literature. Maps are generated with ArcMap to provide an overview of the band's concert tours and facilitate subsequent discussion. Next, hypotheses are developed from mainstream corporate location choice research findings, popular and academic literature on the band, and the application of reasonable intuition. Ordinary least squares regression is employed to empirically test the validity of the hypotheses, followed by a discussion of the results.

The distribution of U2's concerts over the past four decades has been concentrated within a handful of countries. Table 1 breaks down the number of concerts since the band began touring, as well as during the most recent U2360 tour of 2009-11.

Table 1. Distribution of U2 concerts, all-time and U2360 tour (2009-11)

\begin{tabular}{lrr}
\hline Country & All Time & 360 \\
\hline United States & 705 & 33 \\
United Kingdom & 283 & 6 \\
Ireland & 158 & 3 \\
Australia & 69 & 8 \\
Canada & 62 & 9 \\
Germany & 55 & 5 \\
Netherlands & 50 & 2 \\
France & 39 & 4 \\
Italy & 31 & 4 \\
Belgium & 25 & 2 \\
Japan & 22 & 0 \\
\hline
\end{tabular}

\begin{tabular}{lrr}
\hline Spain & $20 \mid$ & 4 \\
Sweden & 18 & 2 \\
New Zealand & 16 & 2 \\
Switzerland & 13 & 2 \\
Mexico & 12 & 3 \\
Argentina & 9 & 3 \\
Denmark & 9 & 2 \\
South Africa & 7 & 2 \\
Austria & 6 & 1 \\
Portugal & 6 & 0 \\
Norway & 6 & 2 \\
Finland & 4 & 2 \\
\hline
\end{tabular}

\begin{tabular}{lll}
\hline Chile & 3 & 1 \\
Poland & 3 & 1 \\
Croatia & 2 & 2 \\
Greece & 2 & 1 \\
Turkey & 2 & 1 \\
Russia & 1 & 1 \\
Bosnia \& & 1 & 0 \\
Herzegovina & 1 & 0 \\
Czech Republic & 1 & 0 \\
Hungary & 1 & 0 \\
Israel & 1 & 0 \\
Monaco & & \\
\hline
\end{tabular}

Data Source: www.u2gigs.com. 
U2's catalogue of concert performances is concentrated in European countries and their former colonies in the Americas and Oceania. In addition, a substantial number of shows have been played in Japan and South Africa. The 110 shows of the most recent $U 2360$ tour reflect a similar spatial pattern, with the exception of Japan being left out of all seven legs. U2's increasingly selective concert geography is incongruent to its more global "geography of inspiration," (Deichmann, 2014). The main difference is that band's lyrics include spatial references to notable events that took place at locations beyond U2's tour circuit, including a number of places in Asia and Africa.

What explains the distribution of U2 shows? A cursory examination of Table 1 yields several plausible hypotheses. Because music represents both a component of culture and a medium for transmitting culture, the band likely targets countries that are culturally similar its home country of Ireland. At culturally similar locations, fans are most likely to attend live performances of Celtic rock. Because live music is a business-not just a career for the performers-- concert shows require an adequate market, which of course favors wealthy countries (Waddell et al., 2007, p. 48). Moreover, because U2's shows typically take place in arenas and stadia with capacities of 20,000-100,000 seats, it is plausible that they are attracted to (if not limited to) sizeable urban areas with such facilities.

Venues with adequate capacities are abundant in the countries listed in Table 1, suggesting that the candidate locations for tour appearances possess large urban populations. When considering the prominent positions of relatively remote Australia, New Zealand, and Japan, one might begin to wonder whether geographic distance can be ignored as a determinant of concert distribution. Finally, nearly every country on the list can be considered relatively "safe", in that the rule of law prevails and major disruptions in public security are relatively uncommon.

Figure 1 takes a closer look at Europe by examining the cities that have hosted more than five shows, with large circles representing "Top 25" destinations and small circles representing other frequent stops. Most prominent are Dublin (U2's home and the city hosting a plurality of performances) and London (\#2, with 105 shows). Other "Top 20" destinations include Paris (22 shows), Rotterdam (19), Birmingham (16), Manchester (14), and Amsterdam (13). Each of these cities is a major European population center that is both culturally and geographically proximate to Dublin.

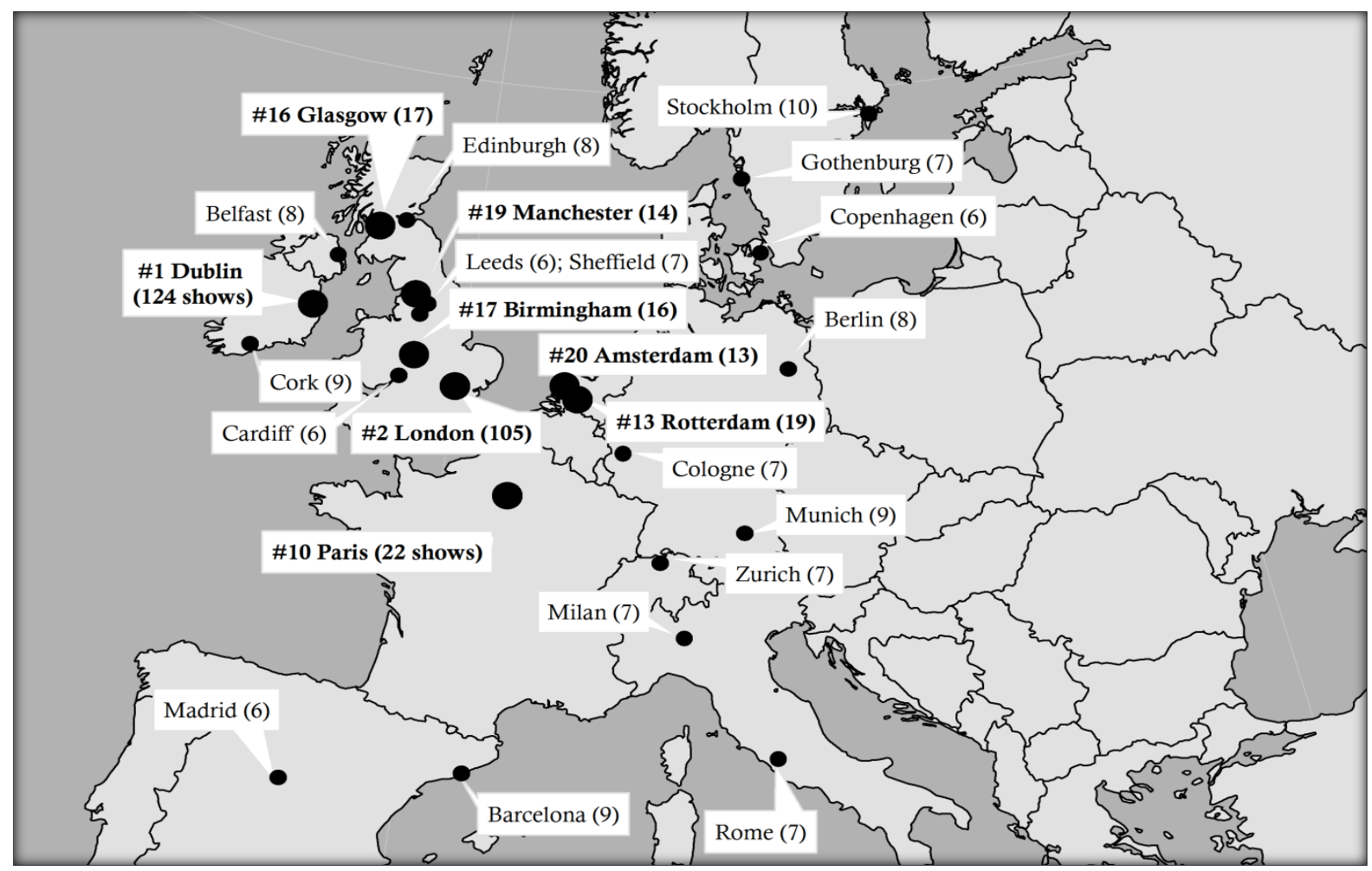

Figure 1. Distribution of U2 concerts in Europe through 2012

Data Source: www.u2gigs.com; author's calculations. 
The necessity of leapfrogging three elaborate "Claw" stages to support the $U 2360$ tour brought to bear the importance of making especially careful logistical decisions, which are highlighted in many portions of Dylan Jones's (2012) From the Ground Up. The book's Chapter 3: “Around the World in 760 Days”, elaborates upon the challenges of moving large quantities of equipment from Europe to Australia via North and South America. As $U 2360$ was an outdoor stadium tour, planning also needed to consider seasonality. Most concert dates correspond to the summer months in the northern and southern hemispheres, respectively.

Another notable observation in Figure 1 is the absence of concerts in many relatively large and affluent cities in Central and Eastern Europe. Within this region, the band has played only a single show in Prague, Budapest, Warsaw, and Moscow, and two each in Zagreb, Chorzow, and Istanbul. Most of these large cities have been bypassed historically by leading performers. Until 1989, most were isolated behind the Iron Curtain, and arguably they have been avoided since that time given that they are peripheral, relatively less affluent, and in some cases associated with higher safety risks.

Ironically, the elaborate stage of the U2360 Tour enabled U2 to play its first ever Russian show in 2010. When asked why U2 had never played Moscow before, Paul McGuinness responded "for the same reason as Hitler and Napoleon actually: it's too far" (Jones, 2012, p. 143). McGuinness added that the three-day drive from Berlin to Moscow had been prohibitive in the past, but now rising prosperity in Eastern Europe has given the band new places to play. The manager therefore hints at a consideration of distance (or, the friction thereof) and market strength as factors entering the band's decision-making process. Both of these variables are often employed in gravity models, as explained below.

Figure 2 shows the distribution of U2 concerts in North America since the band's first tour. North America includes the band's most favored country (USA with 705 shows, including 33 in the $U 2360$ tour and many of the most-played cities. New York leads with 80 shows as U2's most-played city outside of Europe, followed by Los Angeles (50) and Chicago (30). At \#6, Boston enjoys a prominent status for a relatively small city favored by the band as the first US city where U2's music was played on the radio by WBCN, as Bono often reminds local fans at Boston concerts. Boston itself has hosted the band 25 times, while the nearby outdoor stadium at Foxboro has hosted eight shows and neighboring cities Worcester, Massachusetts and Providence, Rhode Island have each hosted nine. Most of the remaining "favorite" cities in North America include cities with large populations and major concert facilities (Toronto, Philadelphia, Atlanta, Montréal, Houston, San Diego, and the San Francisco Bay area, to name a few). Although Boston historically seems to have "special" status with U2, it was omitted from the final leg of 25 North American shows in 2012.

It should be noted that the equipment and staging has changed significantly from tour to tour, so U2's logistical constraints have also evolved over time. During their early tours, U2 shared stages with other bands and carried their own instruments to performances, leaving them relatively footloose with regard to concert sites. During this period, they played venues at relatively obscure places such as Stroud, England, and Hampton Beach, New Hampshire. The $U 2360$ tour lies in extreme contrast, limited to cities with very large football stadiums or large fields (Montréal and Moncton) that could accommodate the enormous stage that became known as 'The Claw' (Jones 2012, p. 32).

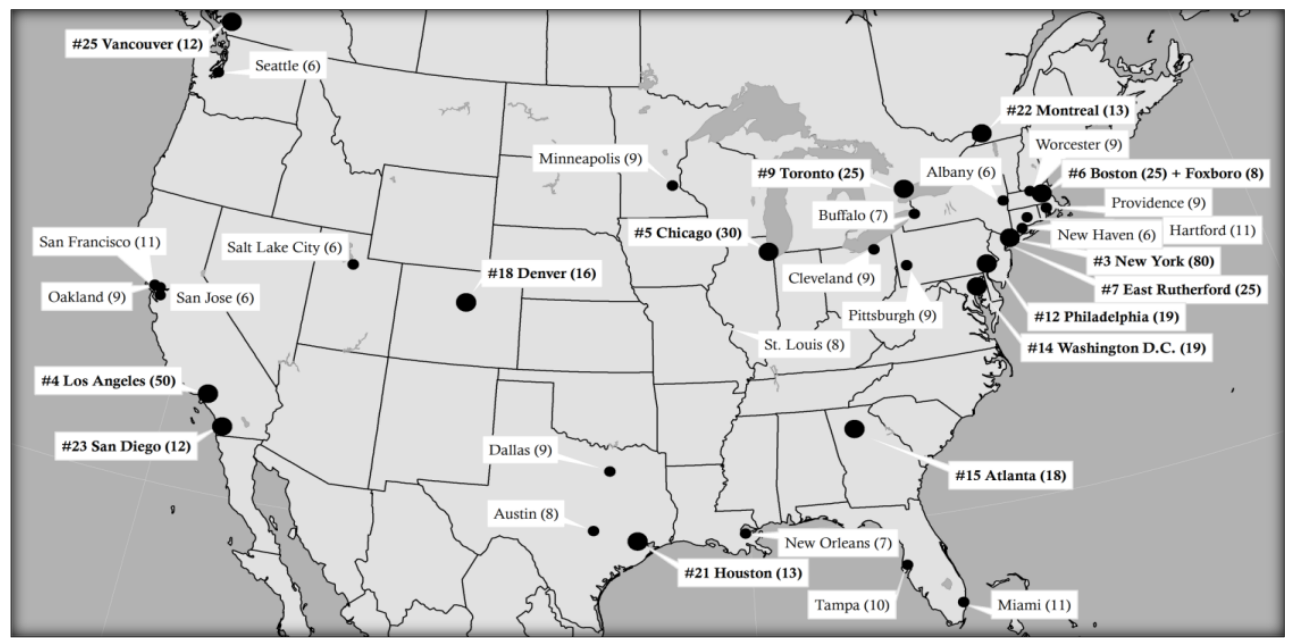

Figure 2. Distribution of U2 concerts in North America through 2012 (Cities with > 5)

Data Source: www.u2gigs.com; author's calculations. 
Outside of Europe and North America, the band has played only a few cities. Because of the widespread distribution of these shows, it does not make sense to portray them on maps. However, Table 2 adds interesting perspective by showing the total number of concerts played per million of population. From this table, we can see that the 705 shows in the USA reflect a well-served market for the band, but by no means is it dominant relative to population. One can also observe the importance of New Zealand $\left(4^{\text {th }}\right)$ and Australia $\left(5^{\text {th }}\right)$ as priority markets for $\mathrm{U} 2$ shows.

Table 2. Leading destinations relative to population

\begin{tabular}{cccc}
\hline Rank & Country & Shows & Shows /mil \\
\hline $\mathbf{1}$ & Ireland & 158 & 41.56171 \\
$\mathbf{2}$ & Monaco & 1 & 31.37083 \\
$\mathbf{3}$ & United Kingdom & 283 & 4.822827 \\
$\mathbf{4}$ & New Zealand & 16 & 4.363180 \\
$\mathbf{5}$ & Australia & 69 & 3.782096 \\
$\mathbf{6}$ & Netherlands & 50 & 3.244530 \\
$\mathbf{7}$ & United States & 705 & 2.639559 \\
$\mathbf{8}$ & Belgium & 25 & 2.440604 \\
$\mathbf{9}$ & Canada & 62 & 2.114593 \\
$\mathbf{1 0}$ & Sweden & 18 & 2.050137 \\
\hline
\end{tabular}

Data Sources: www.u2gigs.com; World Bank (calculations by author).

Australia and New Zealand are very well represented in Table 2 . With 25 shows, Sydney is the band's $8^{\text {th }}$ most frequent city to play, and Melbourne is $11^{\text {th }}$ ( 21 shows). The band has played Auckland, New Zealand ten times, despite the country's small population, and distance of 18,000 kilometers from Dublin. Perhaps the connection can be attributed to New Zealand's strong Anglo-Irish connections, with $28 \%$ of its foreign-born population from the British Isles, and nearly three-quarters of its population being of European descent (Government of New Zealand, 2011). In the case of the $U 2360$ tour, the argument can be made that once the sunk costs of moving the stage to the other side of the globe have been absorbed, the band would be foolish not to maximize its return by meeting the demand of all interested concertgoers.

\section{Methodology: A Modified Gravity Approach}

In the absence of connections to decision-makers in $\mathrm{U} 2$ management, other tools can provide insights to the reasons underlying the geography of performances. Because concert tours represent a form of spatial interaction, it is possible to evaluate what drives them using ordinary least square regression in the same way that other spatial phenomena are examined. Tinbergen (1962) was among the first to use the gravity model in econometrics, adapting Newton's Law of Physics to explain trade flows. Newton's Law holds that two bodies are attracted to one another with a force that is proportional to the product of their masses and inversely proportional to the square of the distance between them. In other words, interaction is more likely to take place between two larger objects that are closer together, than between two smaller ones that are farther away.

In econometrics, "objects" are usually countries, measured by variables such as population size or GDP. The model has been extended to various types of trans-border flows including trade (Lewer \& Van der Berg, 2008), immigration (Ok, 2010), and foreign direct investment (Deichmann, 2013). Anderson (2011) provides a detailed current appraisal of a wide variety of gravity applications, praising the approach as "one of the most successful empirical models in economics."

In the case of U2 performances, one might expect more interaction between a band from Ireland and its immediate neighbor the United Kingdom than with New Zealand, ceteris paribus. This is because New Zealand is a smaller market (mass) located much farther away from Ireland. The principle of distance decay suggests less decreasing likelihood of interaction as distance increases. The simple gravity model is presented in equation 1 as follows: 


$$
\text { Interaction }_{i j}=e\left(M_{i} M_{j} / D_{i j}\right)
$$

Where:

Interaction= any quantifiable event (in this case number of concerts);

$e=$ constant;

$\mathrm{M}=$ mass (GDP or population);

$\mathrm{D}=$ resistance (geographical or cultural distance).

Indeed, Jones (2012) reports that band manager Paul McGuinness holds markets and geographical distance to be important considerations in selecting cities for tours, in line with mainstream gravity model specifications for understanding business interaction (Tinbergen, 1962; Anderson, 2011). Such models can quantitatively unveil the attractiveness of candidate markets, as well as the extent to which they are constrained by geography. While the role of basic mass and resistance are well known as gravity variables, in practice most models are augmented by entering other plausibly relevant variables (Ok, 2010; Anderson, 2011; Deichmann, 2013). Therefore, in the case of U2's site selection, it is justified to question what additional considerations might be at work.

Data for the independent variables are retrieved from the World Bank and World Justice Project, Cultural and geographical distances are calculated by the author as explained in the next section. The dependent variable is the number of performances by country as reported by U2gigs.com's comprehensive database (www.u2gigs.com).

\section{Hypotheses}

Using ordinary least squares regression in SPSS 20, five hypotheses (H1-H5) are set forth below in order to better understand the band's location choices. Beginning with the Boy tour on September 6, 1980, the shows are aggregated to build an adequately sized sample of more than 1600 performances. As the highest grossing concert tour of all time, the extravagantly presented 2009-11 U2360 stadium tour is handled separately in order to provide a comparison with the band's earlier touring behavior.

\section{H1: The number of U2 shows is positively related to market size.}

Following the traditional gravity model, a country's population is seen as a measure of mass. A minimum market threshold exists for large concert events, and Johansson and Bell (2009) argue that the requisite population to favor a strong local music scene may be one million. Florida and Jackson (2010) also find evidence that musicians are attracted to large urban markets within a country. To combine these two considerations, it is argued that a more realistic measurement of national market size is the total population of each country that lives in cities of greater than one million. For this variable, the mean of years 1980-2010 is calculated from the World Development Indicators (World Bank, 2013).

\section{H2: The number of $U 2$ shows is positively related to market strength.}

It is expected that the higher the per capita income of a host country, the more $\mathrm{U} 2$ shows will be performed there. Jones (2012, p. 143) quotes band manager Paul McGuinness as highlighting the importance of "prosperous" markets to make shows possible. Annual mean income for the years 1980-2010 is acquired from the World Development Indicators (World Bank, 2013).

\section{H3: The number of U2 shows is negatively related to geographical distance from Dublin.}

A traditional gravity factor (Anderson, 2011), distance represents an impediment to interaction. This explanation is very straightforward. The transportation of a stage, musical equipment, and large crew long over distances for concerts is both expensive and time consuming. For example, Jones (2012, p. 143) quotes McGuinness as lamenting the considerable time required to move three trucks between Moscow and "the next place you can play (as) not (being) worth it." Of course, the band itself and high-level staff now travel on a jet aircraft while their equipment travels along the surface. Air distances from Ireland to destination country centroids are obtained from www.worldatlas.com.

H4: The number of U2 shows is negatively related to cultural distance from Ireland.

Terry Jordan (1973) cites Indo-European language and religion as the defining cultural characteristics of Europeans that have been exported differentially to other regions of the world. When contemplating cultural distance from Ireland, the importance of both language and religion should be taken into account, especially in light of the band's Christianity-rooted social activism highlighted in Stockman's (2005) book Walk On: The 
Spiritual Journey of U2. Following Deichmann's typology of cultural distance as a product of language and religion (2013) and as illustrated in Table 3, values are defined for each country relative to U2's native Ireland, with values ranging from 1 (closest) to 6 (farthest).

Table 3. Values for cultural distance relative to Ireland

\begin{tabular}{clc}
\hline Score & \multicolumn{1}{c}{ Definition } & Example \\
\hline $\mathbf{1}$ & English speaking "European" (British Isles) & United Kingdom \\
$\mathbf{2}$ & English speaking non-European former colony & South Africa \\
$\mathbf{3}$ & Non English speaking continental Europe & Spain \\
$\mathbf{4}$ & Non English speaking former European colony & Brazil \\
$\mathbf{5}$ & English speaking former colony, non-Christian & India \\
$\mathbf{6}$ & Other (Non English speaking, non-Christian) & China, Japan \\
\hline
\end{tabular}

\section{H5: The number of U2 shows is positively related to order and security.}

Public safety is a pre-requisite for large public gatherings, and minimizing possible risks can be complicated and expensive. Jones (2012, p. 143) observes that in Moscow in 2010, "there were nearly as many security guards at the show as there were genuine fans." Indeed, the 1997 show in Sarajevo put the band at enormous risk (Carter, 1995; Croatia World Network, 2007). It should be remembered that security does not end with the band itself. Waddell et al. (2007) point out that security teams must protect all touring employees (in the case of U2, more than 100), and keep the musical instruments and equipment safe from theft and vandalism. Such security is costly, but its absence can dissuade both performers and concertgoers from certain locations. The variable used here is the World Justice Project Order's Security Index (www.worldjusticeproject.org). As an example, Russia's score is .49, ranked \#93 of 98, while the score for its neighbor Finland is .92 (ranked \#2 out of 98). In the case of this variable, missing values are replaced with the mean across countries.

Given the logical justification to consider the aforementioned variables, they are appended as independent variables to the basic gravity equation, with the dependent variable being the number of shows (first, the total number of shows, and then only those scheduled for the U2360 tour of 2009-2011). In the case of U2 performances, the hypotheses are therefore tested with equation 2:

$$
S H O W S=e+\beta_{1} \text { URBPOP }_{i}+\beta_{2} \text { PCI }_{i}-\beta_{3} \text { GEOG }_{i j}-\beta_{4} C U L T_{i j}+\beta_{5} S E C U R E_{i}
$$

With the following notations:

$e=$ constant for fitting the equation;

$\beta_{1-} \beta_{5}=$ coefficients for each independent variable.

Where:

URBPOP= Country Population in cities of $>1$ million (World Bank, 1980-2010);

PCI= Per Capita Income (World Bank, 1980-2010);

GEOG= Geographical Distance (air kilometers from Dublin);

CULT $=$ Cultural Distance (calculations by author, explained above);

SECURE $=$ Order and security (index by www.worldjusticeproject.org).

Three models are generated in SPSS 20 to evaluate the role of each selected variable, and bivariate correlations between the variables are provided in the Appendix. Model 1 includes all of the independent variables that were posited earlier. In the interest of parsimony, Model 2 uses a stepwise forward algorithm to enter the variables in order of importance and best-fit, omitting those that are problematic due to multi-collinearity as signaled by tolerance and variance inflation factor scores. Finally, Model 3 is run for the U2360 tour only, using the number of shows in 2009-2011 as the dependent variable in order to compare the results with Models 1 and 2. This specification is intended to determine whether any new spatial strategies have been adopted by the band given the logistical constraints of transporting, setting up, and taking down "The Claw", as well as the newfound flexibility afforded by private jets and multiple "home bases." 
Table 4. Coefficients and significance levels of variables in the models

\begin{tabular}{lccc}
\hline & Model 1 Coefficients & Model 2 Coefficients & Model 3 Coefficients \\
\hline Independent Variable $\downarrow$ & SHOWS & SHOWS & SHOWS360 \\
Constant $(\boldsymbol{e})$ & 45.901 & .765 & 2.558 \\
URBPOP & $.000001377^{\mathrm{a}}$ & $.000001396^{\mathrm{a}}$ & $.00000006456^{\mathrm{a}}$ \\
PCI & $.001^{\mathrm{b}}$ & & $.00003443^{\mathrm{c}}$ \\
GEOG & .001 & & .00006794 \\
CULT & $-11.467^{\mathrm{a}}$ & $-2.182^{\mathrm{a}}$ & $-.663^{\mathrm{a}}$ \\
SECURE & .00001319 & & .0000002009 \\
$\boldsymbol{R}^{2}$ & $.293^{\mathrm{a}}$ & $.282^{\mathrm{a}}$ & $.341^{\mathrm{a}}$ \\
\hline
\end{tabular}

${ }^{a}$ Statistically significant at the 0.001 level (two-tailed).

${ }^{\mathrm{b}}$ Statistically significant at the 0.005 level (two-tailed).

${ }^{\mathrm{c}}$ Statistically significant at the 0.05 level (two-tailed).

\section{Analysis of the Models}

As reported in Table 4, the models performed relatively well and with considerable consistency. In all three models, the importance of large urban markets and cultural proximity is upheld with less than a $.1 \%(p=.001)$ chance that the results are spurious. In other words, a country's total population living in cities of over one million is a significant positive predictor of where U2 plays. Reflecting upon the data, countries leading in this category include China, the United States, India, Brazil, Japan, and Mexico, followed by many urbanized European states. Although the band has yet to play China and India, the explanatory value of this variable remains strong. This is because many "un-played" countries remain that are even less urbanized. Empirical evidence supporting the importance of markets as defined here upholds Waddell et al.'s (2007) suggestions as well as the role of large cities as entertainment clusters put forth by Florida et al. (2012).

Cultural distance is also found to be a significant negative predictor of U2 shows. Therefore, as expected cultural proximity is a factor in choosing concert sites. Also as hypothesized, per capita income is a significant predictor of where U2 plays ( $p=.09$ overall, $p=.019$ for $U 2360$ ), although Model 2 suggests it is not as important as market size and cultural proximity. Collinearity statistics for all three models reveal no problematic levels of tolerance or variance inflation factors.

The inclusion of Model 3 shows that geographic distance is a positive but not statistically significant $(p=.143)$ predictor of the $U 2360$ tour of 2009-2011. This means that U2 is actually more likely to play at locations that are farther away from Ireland. This unexpected finding can be reconciled with insights from other variables. In this case, it appears that cultural proximity is strong enough between places that are geographically distant from Ireland (i.e., New Zealand, Australia, Canada, and the United States), to overcome the friction of geographic distance. Hypothesis 3 therefore does not withstand our test.

Counter to expectations, the models yield no evidence that high levels of order and security are a precondition for U2 concerts. Reflecting upon this inconclusive finding with a cursory look at the data, we note that U2 has not played several "safe" countries (those with high scores on this variable) such as Singapore and the UAE (both above .90), while they played several shows in "unsafe" places such as Brazil (.64), Argentina (.60), South Africa (.56), and Mexico (.50), as well as one in Russia (.49), among the least safe countries in the world according to this scale. From this finding, we can conclude that $\mathrm{H} 5$ is not valid, and U2 are indeed willing to play in "less safe" places.

To summarize, Hypotheses 1, 2, and 4 are upheld, confirming the importance of markets and cultural proximity. U2's concert site selection is driven first by market size, measured as total population in large urban areas. However, the band has yet to perform anywhere China, whose enormous market leads the world in this measure. The next important variable is cultural distance, which is a significant and negative driver of site selection, suggesting that cultural proximity indeed draws the band to specific markets outside of Ireland where Western culture thrives. Leading places include the UK, continental Europe, former English colonies with Anglo-Irish roots, and lastly, former European colonies that are culturally similar enough to share an appreciation for the same style of music. Additionally, the role of income is confirmed in attracting the band to perform in wealthy 
markets around the world.

Finally, it is worth noting again that while econometric approaches are useful for understanding general patterns, they can also "miss the forest for the trees"; in other words, they will not necessarily capture all of the reasons the band visits or "avoids" certain countries. For example, speculation exists that U2 has been unable to play some locations because of its outspoken directness on human rights issues. Govern (2013) notes that "after nearly 35 years of touring and playing to more than 1,500 paying audiences in almost 40 countries, one territory the band has yet to play in is China." The author speculates that the Chinese government blackballed U2 from touring in China because of the band's participation in the 1997 Tibetan Freedom concert in New York, noting that the Communist Party forbids performances by musicians who support Tibetan independence.

\subsection{Additional Location Decisions: Site Selection for Concert Videos and Recording Venues}

In addition to evaluating the geography of U2's tours, it is worthwhile to briefly comment on location selection for music videos and concert recordings. Historically, music videos have been produced as a means to market music with the objective of selling recordings and concert tickets. It is therefore unsurprising that U2 has concentrated the filming of nearly all of its music videos in the major music markets of Europe (Ireland, Sweden, Berlin, France, Spain) and America (California and Las Vegas). The band has not always had the means for such extravagance. Especially during the band's early years, filming locations were constrained by finances. The "Rattle and Hum" production was filmed throughout the United States and features concert footage from McNichols Arena in Denver and Sun Devil Stadium in Tempe, Arizona. McGee $(2008,105)$ points out that the band originally planned to film in Buenos Aires, but financial limitations prevented filming in South America.

Over the past fifteen years, however, it appears that financial success has enabled the band to become more footloose with regard to site selection. Footage from the Charles de Gaulle airport in Paris ("Beautiful Day", 2001), Spain ("Vertigo", 2005), and the south of France ("Electrical Storm", 2007), indicate that U2 targets its music and ideas at established markets. Evidently, the band is less constrained by finances at the present than they were in the past.

Similarly, the location choices for U2's other live concert films mimics its leading concert markets, logically in an attempt to sell media to large populations of enthusiasts. Concert recordings include Denver (Under A Blood Red Sky, 1983), Sydney (ZooTV, 1992), Mexico City (PopMart, 1997), Boston (Elevation, 2001), Slane Castle, Ireland (U2 Go Home, 2001), Chicago (Vertigo, 2005), and Los Angeles (U2360, 2012). The selection of these cities for the band's concert DVD recordings is unsurprising given the previous section's discussion of tour site selection. The 2008 avant garde three-dimensional $U 23 D$ "live" video should also be mentioned here. Filmed during the northern hemisphere's winter, most of the concert footage is from Buenos Aires, São Paulo, and Santiago, with some shots also from Mexico City and Melbourne, Australia.

U2 has recorded studio albums in Dublin, Los Angeles, Berlin, the south of France, and Morocco, and most recently (2014) in New York. Many of these places reflect the creative clusters discussed by Brandellero and Pfeffer (2011) and Florida, Mellander, and Stolarick (2012). Indeed, stepping spatially into footsteps of greatness seems to be important for U2. As one example, Bono proudly points out that U2 recorded Achtung Baby (1991) at Hansa Ton studios in Berlin, where artists who inspired the band-including Iggy Pop, David Bowie and Depeche Mode--had recorded earlier. Additionally, the Berlin Wall had just come down in November 1989, and according to Flanagan (1995), the like so many Germans, the band recognized the need to head in a new direction and "dream it all up again." In an effort to put the The Joshua Tree in their creative past, U2 anticipated that the excitement and optimism of Berlin at such a pivotal point in history might inspire its new material.

\section{Concluding Remarks}

This paper's main contribution is the application of conventional approach in economic geography to a sub-theme of music geography, an area of analysis traditionally dominated by cultural geographers. Specifically, the paper demonstrates the usefulness of an adapted gravity model as a tool for evaluating the geography of global tours by $\mathrm{U} 2$. The models confirm the importance of market factors and cultural proximity in performance site selection. These conclusions complement Johannson and Bell's (2014) findings on North American touring circuits, but providing evidence from very different data. U2's case is particularly instructive because of the band's longevity and enduring commercial success. This study adds credence to the role of markets and culture based upon 33 years of data on a single rock band's global location decisions. Moreover, the approach employed here can readily be replicated for other performing acts. Such research is valuable for understanding the geography of tour circuits, which can provide insights for academics and future tour planners alike. As the nature of the music industry continues to evolve in favor of touring per Boyd's (2013) expectation, U2 is increasingly motivated by concert revenue rather than selling its recordings. Clear evidence for this can be found in U2's 
2014 new release giveaway of Songs of Innocence to up to half a billion listeners (O'Shea, 2014). Moreover, live performances offer a product that cannot be matched by recordings alone (Earl, 2001), and will likely continue to do so for the foreseeable future.

Following Nash and Carney's (1996) typology of sub-disciplines within music geography, the contributions here lie in the area of location analysis. Evidence is found that U2's performance site selection favors concentrations of large urban populations, cultural proximity to Ireland, and host country income. The findings help explain why the band holds most of its performances in major cities of Europe, the Americas, and Oceania, at the expense of mainland Asia and Africa. A brief descriptive analysis of concert videos site selection also provides insights underscoring the importance of markets. "Live" recordings of performances in Denver, Sydney, Mexico City, Boston, Chicago, and Los Angeles roughly mimic the global map of U2's tours, and provide insights into the band's marketing strategy.

Some limitations to this study should be acknowledged. Secondary data such as those made available by the World Bank (2013) are collected and reported by national governments, which often use disparate data-collection and reporting methodologies. Although a logical extension of this work would be to use city-level data to analyze tours as done by Florida et al. (2012), such data would be difficult to obtain at an international level and even more subject to limitations, beginning with the very definition of urban areas, which varies by country. Even within a single country such as the United States, considerable variation exists on how cities are defined, and comparability becomes more of a challenge at a global scale.

The methodology employed here identifies relationships between variables to detect and explain human decision-making, with compelling results. Nevertheless, Paul McGuinness, band manager through the end of the U2360 tour (2011), ultimately holds the answers to the questions raised in this study. However, in the absence of direct contact with Mr. McGuinness, his public statements and the literature on U2 are invaluable in specifying the models used in this exercise. Unsurprisingly, the results presented here provide empirical support for many of his statements, especially those relating to market affluence and logistical challenges (Jones, 2012).

Finally, globalization hints that the parameters of concert tours are dynamic. Globally performing acts are increasing in number and in wealth, and transportation infrastructure will likely improve their mobility, as well as the mobility of concertgoers. For this reason, great potential exists for future research in the area of location selection for concert tours. In addition, whenever possible, open-ended interviews with decision-makers would yield the most authoritative answers. These and other developments invite a replication or expansion of this study to compare its findings with research on other global performers as the industry continues to change.

\section{References}

Anderson, J. E. (2011). The Gravity Model. Boston College/NBER Working Paper. Retrieved June 10, 2013 from https://www2.bc.edu/ anderson/GravityModel.pdf

Boyd, B. (2013). U2 and Paul McGuinness: The End of the Affair. The Irish Times (Nov $16^{\text {th }}$ ). Retrieved November 20, 2013 from http://www.irishtimes.com/life-and-style/people/

Boyle, C. (2011). Tax, Royalties and Rock'n'Roll: Why U2 Face Protests. CNBC Online. Retrieved April 10, 2013 from http://www.cnbc.com/id/43305550

Brandellero, A., \& Pfeffer, K. (2011). Multiple and Shifting Geographies of World Music Production. Area, 43(4), 495-505. http://dx.doi.org/10.1111/j.1475-4762.2011.01057.x

Carney, G. (1998). Music Geography. Journal of Cultural Geography, 18(1), 1-27. http://dx.doi.org/10.1080/08873639809478309

Carter, B. (2005). Fools Rush In. New York: Wenner Publishing.

Croatia World Network. (2007). U2 in Sarajevo: Ten Years after September 23, 1997. Retrieved from http://www.croatia.org/crown/articles/9273/1/U2-in-Sarajevo-10-Years-After-September-23-1997.html

Davis, S. (1992). The Songwriter's Idea Book. Blue Ash, Ohio: F\&W Media.

De Mooij, R., \& Enderveen, S. (2003). Taxation and Foreign Direct Investment: A Synthesis of Empirical Research. International Tax and Public Finance, 10, 673-693. http://dx.doi.org/10.1023/A:1026329920854

Deichmann, J. (2013). Origins of Foreign Direct Investment in Croatia: Application of an Expanded Gravity Model. In Karasavvoglou, A., \& Polychronidou, P. (Eds.), Balkan and Eastern European Countries in the Midst of the Global Economic Crisis (pp. 3-21). Berlin: Springer. http://dx.doi.org/10.1007/978-3-7908-2873-3_1 
Deichmann, J. (2014). Miami, New Orleans, London, Belfast, and Berlin: The Geography of U2's Music Lyrics. Working paper (unpublished).

Earl, P. (2001). Simon's Travel Theorem and the Demand for Live Music. Journal of Economic Psychology, 22(3), 335-358. http://dx.doi.org/10.1016/S0167-4870(01)00037-X

Florida, R., \& Jackson, S. (2010). Sonic City: The Evolving Economic Geography of the Music Industry. Journal of Planning Education and Research, 29(9), 310-321. http://dx.doi.org/10.1177/0739456X09354453

Florida, R., Mellander, C., \& Stolarick, K. (2012). Geographies of Scope: An Empirical Analysis of Entertainment, 1970-2000. Journal of Economic Geography, 12, 183-204. http://dx.doi.org/10.1093/jeg/lbq056

Govern, A. (2013). Off the Record. Vol. 13 \#560. Retrieved April 3, 2013 from http://www.atu2.com

Government of New Zealand. (2011). The Social Report: People. Retrieved November 20, 2013 from http://www.socialreport.msd.govt.nz/people/ethnic-composition-population.html

Johansson, O., \& Bell, T. (2009). Sound Society and the Geography of Popular Music. Farnham: Ashgate.

Johansson, O., \& Bell, T. (2014). Touring Circuits and the Geography of Rock Music Performance. Popular Music and Society, 37(3), 313-337. http://dx.doi.org/10.1080/03007766.2013.798554

Jones, D. (2012). From the Ground Up: U2360 Tour. London: Random House.

Jordan, T. (1973). The European Culture Area. New York: HarperCollins.

Lewer, J., \& Van den Berg, H. (2008). A Gravity Model of Immigration. Economics Letters, 99(1), 164-167. http://dx.doi.org/10.1016/j.econlet.2007.06.019

McGee, M. (2008). U2: A Diary. London: Omnibus Press.

Nash and Carney. (1996). The Seven Themes of Music Geography. The Canadian Geographer, 40(1), 69-84. http://dx.doi.org/10.1111/j.1541-0064.1996.tb00433.x

O'Shea, J. (2004). What does U2 Giving Album Away for Free Mean for the Music Industry and Young Artists? Independent Music News. Retrieved September 28, 2014 from http://www.independent.ie/entertainment

Ok, S. (2010). What Determines Intra-EU Trade? The Gravity Model Revisited. International Research Journal of Finance and Economics, 39, 244-250.

Stockman, S. (2005). Walk On: The Spiritual Journey of U2. Orlando, FL: Relevant Media Group.

Tinbergen, J. (1962). Shaping the World Economy: Suggestions for an International Economic Policy. New York: Twentieth Century Fund.

U2gigs.com. (2012). Database of U2 performances. Retrieved October 23, 2013 from http://www.u2gigs.com/all-u2-tours.html

Waddell, R., Barnet, R., \& Berry, J. (2007). The Business of Concert Promotion and Touring. New York: Crown Publishing.

Wood, N., Duffy M., \& Smith, S. (2007). The Art of Doing (Geographies of) Music. Environment and Planning D: Society and Space, 25, 867-889. http://dx.doi.org/10.1068/d416t

World Bank. (2013). World Development Indicators. Retreived May 25, 2013 from http://data.worldbank.org/data-catalog/world-development-indicators 


\section{Appendix}

Appendix 1. Simple bivariate correlations ( $\mathrm{N}=196)$

\begin{tabular}{|c|c|c|c|c|c|c|c|}
\hline & & SHOWS & URBPOP & PCI & GEOG & CULT & RISK \\
\hline \multirow[t]{6}{*}{ Pearson Correlation } & SHOWS & 1.000 & .442 & .231 & -.080 & -.308 & -.020 \\
\hline & URBPOP & .442 & 1.000 & .043 & .067 & -.033 & -.038 \\
\hline & PCI & .231 & .043 & 1.000 & -.317 & -.415 & -.021 \\
\hline & GEOG & -.080 & .067 & -.317 & 1.000 & .416 & .011 \\
\hline & CULT & -.308 & -.033 & -.415 & .416 & 1.000 & .044 \\
\hline & RISK & -.020 & -.038 & -.021 & .011 & .044 & 1.000 \\
\hline \multirow[t]{6}{*}{ Sig. (1-tailed) } & SHOWS & . & .000 & .001 & .134 & .000 & .393 \\
\hline & URBPOP & .000 & . & .273 & .175 & .322 & .298 \\
\hline & PCI & .001 & .273 & . & .000 & .000 & .385 \\
\hline & GEOG & .134 & .175 & .000 & . & .000 & .438 \\
\hline & CULT & .000 & .322 & .000 & .000 & . & .269 \\
\hline & RISK & .393 & .298 & .385 & .438 & .269 & \\
\hline
\end{tabular}

\section{Copyrights}

Copyright for this article is retained by the author(s), with first publication rights granted to the journal.

This is an open-access article distributed under the terms and conditions of the Creative Commons Attribution license (http://creativecommons.org/licenses/by/3.0/). 